\title{
Evolution Law of Floor Fracture Zone above a Confined Aquifer Using Backfill Replacement Mining Technology
}

\author{
Shan Ning $\mathbb{D}^{1,2}$ Weibing Zhu $\mathbb{D}^{1,2}$ Xiaoyong Yi, ${ }^{1,2}$ and Laolao Wang ${ }^{1,2}$ \\ ${ }^{1}$ State Key Laboratory of Coal Resources and Safe Mining, China University of Mining and Technology, Xuzhou, China \\ ${ }^{2}$ School of Mines, China University of Mining and Technology, Xuzhou, China \\ Correspondence should be addressed to Weibing Zhu; cumtzwb@cumt.edu.cn
}

Received 9 July 2020; Revised 9 September 2020; Accepted 15 February 2021; Published 3 March 2021

Academic Editor: Constantinos Loupasakis

Copyright (c) 2021 Shan Ning et al. This is an open access article distributed under the Creative Commons Attribution License, which permits unrestricted use, distribution, and reproduction in any medium, provided the original work is properly cited.

\begin{abstract}
Disturbances owing to coal mining result in the movement and failure of floor strata. Mining-induced fractures within the floor may propagate to the confined aquifer, thereby causing water inrush disasters. In this study, we propose using strip mining and backfill replacement mining above the confined aquifer to investigate the failure depth of the floor. The problem is simplified as a distributed force model on a half-plane body. First, the stress disturbance of the floor during strip mining is calculated and the results are combined with the von Mises yield criterion. Then, the destruction of the floor after replacing the remaining coal pillars is explored. The results show that the widths of the strip mining face and coal pillars play an important role in affecting the failure depth of the floor: the greater the width, the larger the failure depth. Based on the parametric study results, the mining face and retention coal pillar width of $20 \mathrm{~m}$ is sufficient to prevent the occurrence of water inrush accidents. After the replacement of the remaining coal pillars, the failure area of the floor rock mass increases, but the maximum failure depth remains unchanged. Finally, we employed field measurement techniques at the Bucun coal mine to monitor the shear and vertical strains of the floor. The data collected was compared with the predicted results obtained from the proposed theoretical model. Good agreement was found between the monitoring and calculation results, which demonstrate the effectiveness of the proposed method.
\end{abstract}

\section{Introduction}

During the mining of a coal seam above a confined aquifer, there are many incidents of water inrush from the floor resulting in huge casualties and economic loss [1-3]. Excavation activities cause floor damage, and the formation of water channels is the main cause of water inrush [4]. To ensure safety during mining, the widely adopted method called strip mining is used [5]. Strip mining can effectively reduce the failure depth of floor strata and avoid the occurrence of such accidents. Given that strip mining needs a certain width of coal pillar to maintain the stability of mining space, the recovery rate of coal resources is lower than the traditional caving method. After strip mining, backfilling with high water content material helps to reduce the loss of coal resources and ensure the safety of the process [6].

In general, coal mining activities change the stress distribution characteristics of surrounding rock [7-9]. When the stress of the floor strata exceeds the ultimate strength, cracks appear in its interior part $[10,11]$. As the excavation intensity increases, the cracks develop gradually and eventually penetrate the strata between the working face and the confined aquifer [12-14]. Strip mining can effectively reduce the disturbance to the surrounding rock and the failure depth of the floor [15]. Previous studies have suggested the technology of grouting reinforcement of the floor, which can improve the strength of the floor rock mass and avoid the generation of permeable passages $[16,17]$.

After strip mining, the sustained strength of the stope surrounding rock decreases as time increases $[6,18,19]$. As the rock failure develops, it is possible to form a new permeable passage. Then, backfilling the goaf in time to improve the stress environment of surrounding rock can eliminate the continuous development of floor failure zone [20-22]. According to experiments and field observations, the stress concentration at the surrounding rock of the goaf decreases 


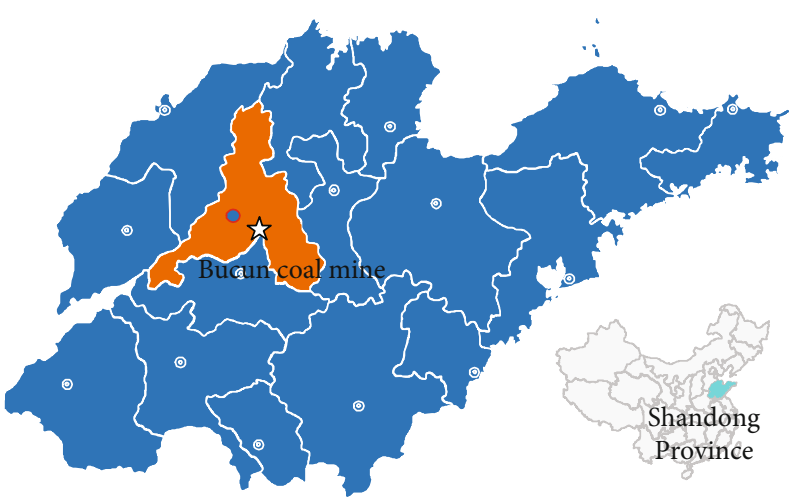

(a)

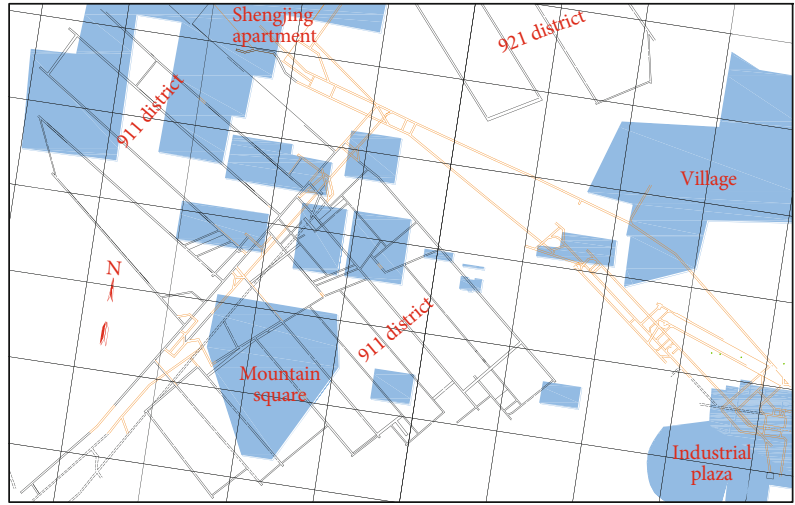

(b)

Figure 1: Bucun coal mine geographic information map: (a) location of Bucun coal mine; (b) location of the down hole working face and surface buildings.

after backfilling $[23,24]$. Simultaneously, the failure of the floor rock mass is under control and the floor accident can be effectively prevented [25-27]. Moreover, the deformation and settlement of overlying strata decreased $[28,29]$.

Previous studies focused on the problem of water inrush and subsidence caused by coal mining. Additionally, significant research has been done on strip mining and goaf backfill to prevent water inrush. However, the recovery of the abandoned coal pillar and floor failure after the backfill replacement mining has not been considered. When backfilling material is used to recover the abandoned coal pillar, the coal seam floor will be affected by mining, and new deformations and destruction will occur at the floor strata. In particular, in the case of the coal seam above a confined aquifer, the floor is easy to form a water diversion channel under the influence of multiple mining, resulting in the problem of water inrush.

This study examines the stress distribution on the floor boundary during strip and backfill replacement mining above a confined aquifer. The two types of mining are simplified as mechanical problems under different boundary conditions. Using the elastic mechanics method, the stress distribution and floor failure evolution in the process of strip mining and backfill replacement mining are studied, respectively. As a result, the study provides theoretical guidance for safe mining of coal seams above a confined aquifer at the Bucun coal mine as well as overcoming shortcomings of the low extraction rate of strip mining and reducing the wastage of coal resources.

\section{Backfill Replacement Mining Technology}

2.1. Background. To begin with, the Bucun coal mine belongs to the Zibo Mining Group, located in the Jinan Shandong Province as presented in Figure 1. Its industrial square is in the town of Bucun, which is distributed in four townships: Bucun, Wenzu, Shengjing, and Xusheng. More than $80 \%$ of the mine resources are No. 9 and No. 10 coal seams, which are mostly under buildings and threatened by water inrush from the floor. Therefore, the way to mine those coal seams safely and effectively is a major technical problem for Bucun coal mine.

From 2005 to 2009, strip mining was used to mine underground coal under confined water pressure in the 911 district of Bucun coal mine. The width of the excavated coal pillar was between 6 and $20 \mathrm{~m}$, the width of the retained coal pillar was 10 to $25 \mathrm{~m}$, and the recovery rate was only $34.2 \%$. During the period of 2010-2011, 921 district used inclined strip mining to extract the coal above confined aquifer. The widths of the excavated and the retained pillars were $20 \mathrm{~m}$ and $25 \mathrm{~m}$, respectively, and the recovery rate was $44.4 \%$. The average recovery rate of the two mining areas was $39.3 \%$, while many coal resources remained underground.

2.2. Floor Water Inrush. Since the 1970 s, the Bucun coal mine has been mining No. 9-2 coal seam threatened by a confined aquifer. The mining area of these coal seams was approximately $5.42 \mathrm{~km}^{2}$, and the lower level of mining was $-372.8 \mathrm{~m}$. Moreover, there have been two instances of floor water inrush reaching a maximum amount of $60 \mathrm{~m}^{3} / \mathrm{h}$.

Further, the 9110 working face had been mined since July 15, 2004, and strip mining had been adopted (Figure 2). Initially, the designed mining width was $40 \mathrm{~m}$. On July $31^{\text {st }}$, after mining $33 \mathrm{~m}$ in the 9110 working face, water inrush occurred at the back of the working face. The initial water volume was $150 \mathrm{~m}^{3} / \mathrm{h}$, while the maximum reached $334.8 \mathrm{~m}^{3} / \mathrm{h}$. After this incident, grouting was used to treat the water inrush, and the production was resumed in August 2005.

After this incident, the distribution of the aquifer on the floor of the area was investigated in detail. According to the geological exploration data, it consisted of, mainly, the Xushang sandstone, Xujiazhuang limestone, and Ordovician limestone aquifers. The thickness of the Xushang sandstone aquifer was 0 to $14.07 \mathrm{~m}$, the distance from the coal seam was 43.54 to $63.77 \mathrm{~m}$, and the average distance was $54.40 \mathrm{~m}$. It was, generally, attached to Xujiazhuang limestone and had a thickness of approximately 0 to $1.29 \mathrm{~m}$ shale or clay shale with a maximum water pressure of $3 \mathrm{MPa}$. In addition, 


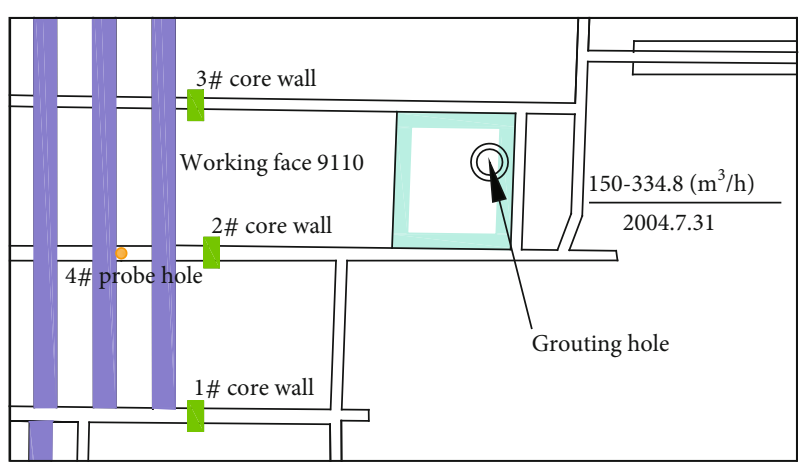

FIgURE 2: Water inrush position of 9110 working face.

the thickness of Xujiazhuang limestone aquifer was 8.45 to $12.19 \mathrm{~m}$, with an average of $10.47 \mathrm{~m}$. The distance from No. 9-1 coal seam was 52.17 to $71.50 \mathrm{~m}$, and the average distance was $61.59 \mathrm{~m}$. The distance from the lower part of the Ordovician limestone aquifer was 9.79 to $12.45 \mathrm{~m}$, with an average of $10.81 \mathrm{~m}$. This type of limestone was generally rich in water and had a certain regionalization. It was mainly recharged by the Ordovician limestone aquifer while recharging upwards the Xushang sandstone aquifer. The maximum water inrush coefficient and maximum water pressure were $0.132 \mathrm{MPa} / \mathrm{m}$ and $0.132 \mathrm{MPa} / \mathrm{m}$, respectively, and the maximum water pressure was $6.3 \mathrm{MPa}$.

Moreover, the main aquifer in the coal seam floor was the Ordovician limestone, which was rich in water and had good recharge conditions that made it the main water supply source of every aquifer in the lower part of the coal seam. The average distance from the No. 9-1 coal seam was $82.87 \mathrm{~m}$, and the average distance from the Xujiazhuang limestone was $10.81 \mathrm{~m}$. The maximum water inrush coefficient of the Ordovician limestone was $0.082 \mathrm{MPa} / \mathrm{m}$, and the maximum water pressure of the Ordovician limestone aquifer was $6.52 \mathrm{MPa}$.

Based on the characteristics of mining above the confined aquifer and under the buildings in the Bucun coal mine, strip mining method was adopted. The reason is that the width of the working face in strip mining is narrow, causing smaller damage to the floor, which can achieve safe mining above the confined aquifer [30]. Additionally, strip mining can effectively control surface subsidence, with a reduction rate between $80 \%$ and $90 \%$ [31].

2.3. Backfill Replacement Mining. Due to the low recovery ratio of strip mining, many pillars remain underground. To further improve the recovery rate of coal resources, high water content material is used to fill the goaf and replace the retained coal pillar $[6,31]$. The mining plan is divided into three main steps, and Figure 3 illustrates the mining and backfilling process.

At first, the strip mining method is used to recover the coal seam (Figure 3(a)). The coal seam is mined according to the design plan, and the goaf and coal pillars are distributed at intervals after mining. In the second step, the goaf is filled with high water content material (Figure 3(b)). The fill- ing body and the coal pillar form an integral unit to support the roof. After the filling body acquires certain strength, the remaining coal pillars are mined at intervals (Figure 3(c)). Then, in the third part, after the mining of the coal pillar, the newly formed goaf is filled. After the filling body has certain strength, all the remaining coal pillars are recovered individually (Figure 3(d)).

Throughout the process of replacing the remaining coal pillar with filling material, the floor is affected by multiple mining, which can easily lead to the increase of the floor fracture zone to form a new permeable passage. As shown in Figure 3, the shallow area of the floor affected by coal seam mining is damaged. Since the deep part of the floor is less affected by mining, the rock mass still maintains a good elastic state, which can block the inrush of confined water. Under the influence of multiple mining, the failure area of the floor and the risk of water inrush accidents in the working face will increase. To avoid that, the law of floor fracture, in the process of filling and replacement of coal pillars, must be examined.

\section{Mechanical Model}

3.1. Stress Analysis of Floor Rock Mass. Through the use of strip mining, the weight of the overburden is transferred to both sides of the coal pillars and the load on each pillar is elevated. At this point, the load is given by the following equation:

$$
q=\frac{l+m}{l} \sum_{i=0}^{n} \gamma_{i} h_{i},
$$

where $q$ is the load on the pillar (in $\mathrm{MPa}$ ), $l$ and $m$ are the widths of the pillar and the mining width (in meters), respectively, $\gamma_{i}$ is the bulk density of layer $i^{\prime}$, and $h_{i}$ is the thickness of layer $i$ (in meters).

Due to the impact of coal seam excavation, the stress over the floor changes. The overburden stress passes through the coal pillars, which in turn causes redistribution of the stress on the floor of the coal bed. Many researchers use the halfplane body model to study the stress disturbance of the floor $[7,32]$. According to these studies, the influence of the strip coal pillars on the floor is simplified as shown in Figure 4.

The stress concentration occurs beneath the coal pillar, and when the rock mass stress exceeds the strength limit, the rock mass enters the plastic state and it can be destroyed.

According to Saint Venant's principle, the surface force acting on the boundary will change significantly near the system of force while the influence at a distance can be ignored. Therefore, the force acting on any area on the floor boundary only affects the shallow area of the floor rock mass. The influence decreases significantly at a considerable distance from this area. Within the scope of influence, the risk of rock mass failure is higher. In particular, when the aquifer is significantly affected by mining, water inrush is very likely to occur.

3.2. Mechanical Model. As shown in Figure 5, strip mining is simplified to a model of distributed force on the semiplanar body boundary. The force on the floor boundary is mainly 


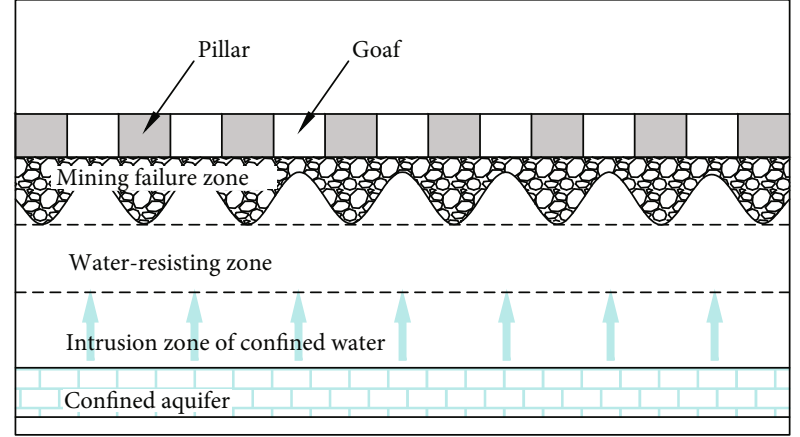

(a)

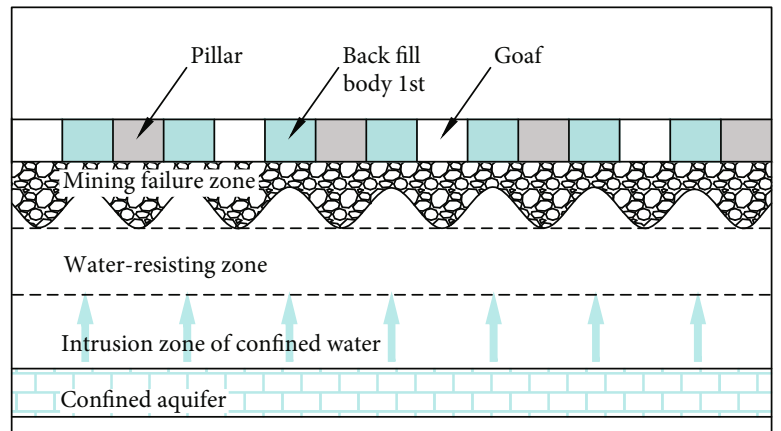

(c)

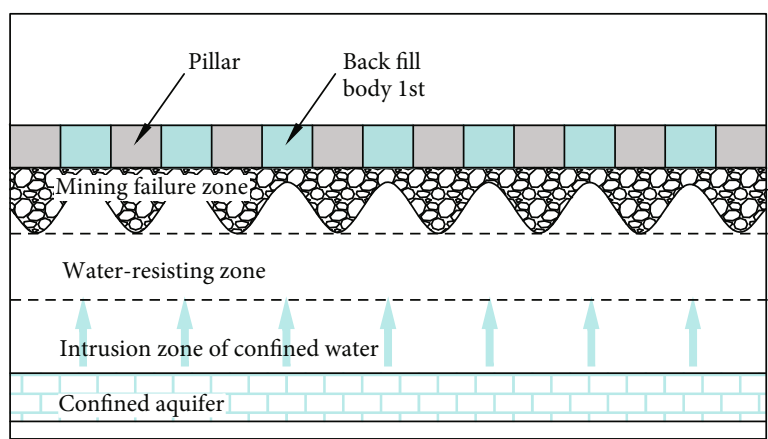

(b)

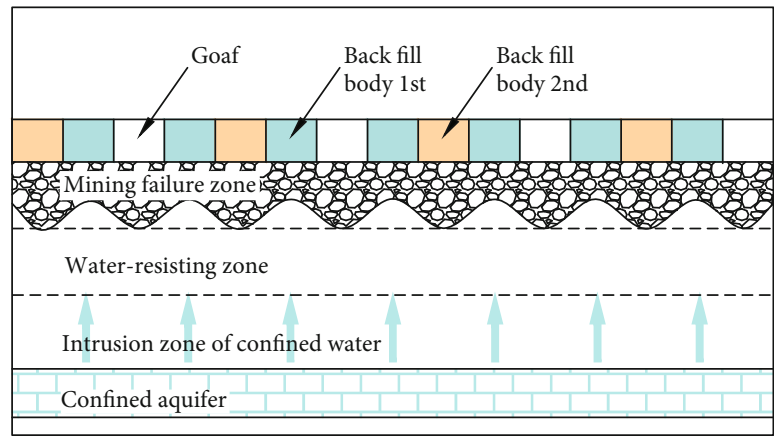

(d)

FIGURE 3: Schematic diagram of the backfill replacement mining above a confined aquifer: (a) strip mining, (b) goaf filling, (c) the first backfill replacement mining, and (d) the second backfill replacement mining.

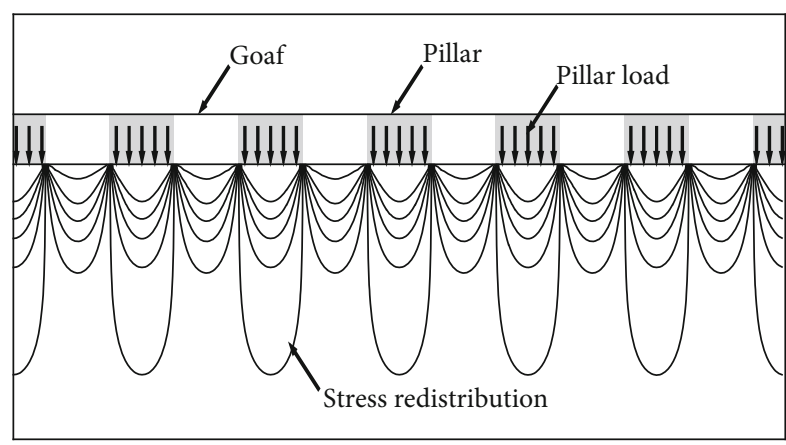

FIGURE 4: Simplified model diagram of the stress redistribution after strip mining.

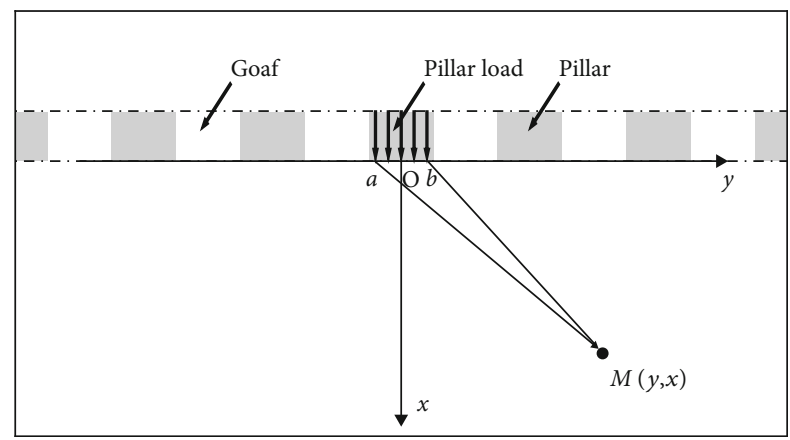

FIGURE 5: A model of half-plane body subjected to distributed force on the boundary. transmitted by the overlying strata through the coal pillar. The floor is regarded as a half-plane body, and the load distributed on it is regarded as a force on the half-plane body.

First, the impact of one coal pillar on floor rock mass is calculated. According to elasticity theory, the stress caused by the uniformly distributed force on the boundary of the half plane at any point in the region is estimated using the following equations:

$$
\begin{aligned}
& \sigma_{x}=-\frac{2}{\pi} \int_{a}^{b} \frac{q x^{3} d \xi}{\left[x^{2}+(y-\xi)^{2}\right]^{2}}, \\
& \sigma_{y}=-\frac{2}{\pi} \int_{a}^{b} \frac{q x(y-\xi)^{2} d \xi}{\left[x^{2}+(y-\xi)^{2}\right]^{2}}, \\
& \tau_{x y}=-\frac{2}{\pi} \int_{a}^{b} \frac{q x^{2}(y-\xi) d \xi}{\left[x^{2}+(y-\xi)^{2}\right]^{2}},
\end{aligned}
$$

where $a$ and $b$ are the lower and upper limits of the interval where the coal pillar is located.

For strip mining, the influence of other coal pillars should be considered when calculating the stress of any point on the floor. According to the principle of superposition, the effect of different loads on a body is equal to the accumulated influence of each group of loads alone. Therefore, the stress caused by every coal pillar in the mining area at point $M$ 
can be superimposed, and the calculation formula is as follows.

$$
\left.\begin{array}{c}
\sigma_{x}=-\sum_{i=0}^{n}\left(-\frac{2}{\pi} \int_{a_{i}}^{b_{i}} \frac{q x^{3} d \xi}{\left[x^{2}+(y-\xi)^{2}\right]^{2}}\right), \\
\sigma_{y}=\sum_{i=0}^{n}\left(-\frac{2}{\pi} \int_{a_{i}}^{b_{i}} \frac{q x(y-\xi)^{2} d \xi}{\left[x^{2}+(y-\xi)^{2}\right]^{2}}\right), \\
\tau_{x y}=\sum_{i=0}^{n}\left(-\frac{2}{\pi} \int_{a_{i}}^{b_{i}} \frac{q x^{2}(y-\xi) d \xi}{\left[x^{2}+(y-\xi)^{2}\right]^{2}}\right),
\end{array}\right\}
$$

where $a_{i}$ and $b_{i}$ are the lower and upper limits of the interval where a coal pillar is located. The expansion form of equation (3) is presented in

$$
\left.\begin{array}{l}
\sigma_{x}=\sum_{i=0}^{n}-\frac{q}{\pi}\left(\begin{array}{c}
-\frac{x\left(a_{i}-y\right)}{x^{2}+\left(a_{i}-y\right)^{2}}-\arctan \left[\frac{a_{i}-y}{x}\right] \\
+\frac{x\left(b_{i}-y\right)}{x^{2}+\left(b_{i}-y\right)^{2}}+\arctan \left[\frac{b_{i}-y}{x}\right]
\end{array}\right], \\
\sigma_{y}=\sum_{i=0}^{n}-\frac{q}{\pi}\left[\begin{array}{c}
\frac{x\left(a_{i}-y\right)}{x^{2}+\left(a_{i}-y\right)^{2}}-\arctan \left[\frac{a_{i}-y}{x}\right] \\
+\frac{x\left(y-b_{i}\right)}{x^{2}+\left(b_{i}-y\right)^{2}}+\arctan \left[\frac{b_{i}-y}{x}\right]
\end{array}\right], \\
\tau_{x y}=\sum_{i=0}^{n}-\frac{q}{\pi}\left(-\frac{x^{2}}{\left(a_{i}-y\right)^{2}+x^{2}}+\frac{x^{2}}{\left(b_{i}-y\right)^{2}+x^{2}}\right) .
\end{array}\right\}
$$

For the convenience of the calculations, the coal pillars are distributed symmetrically on the $x$-axis (Figure 6) so the action interval of a coal pillar is equal to

$$
\left[a_{i}, b_{i}\right]=\left[\frac{m}{2} \pm(m+l),\left(\frac{m}{2}+l\right) \pm(m+l)\right]
$$

where $i=0,1,2,3 \cdots$.

The $x$-axis interval of the study area is $(x \in[-100,100]$, $y \in[0,50])$, and the rock mass is studied within a $50 \mathrm{~m}$ depth. To ensure the boundaries of the study area are consistent with the stress and failure laws in the middle, the calculation interval should be much larger than the study interval. According to the experiment, when the interval of the calculation area is $(x \in[-300,300], y \in[0,50])$, the stress distribution law of the floor does not change.

Python is used to visualize the stress distribution of the floor. A script calculates the stress at each position and then employs Matplotlib to display the calculation results and generate contour and line maps. The calculations shown in this paper are all performed using Python 3.0. The stress values are generated in a $1 \mathrm{~cm}$ grid in the $\mathrm{X}$ and $\mathrm{Y}$ directions to ensure sufficient accuracy and resolution.

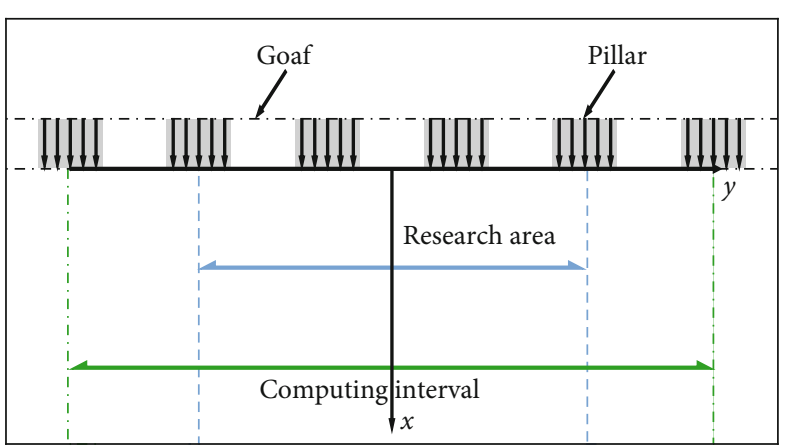

FIgURE 6: Calculation and study intervals.

3.3. Maximum Shear Stress. After the coal seam is mined, the stress is redistributed on the floor. The maximum shear stress has a significant effect on the deformation and failure of the rock mass and can also characterize the shear failure of the rock body to a certain extent. The distribution characteristics are typical when analyzing the deformation and failure of the floor. At the plastic stage, the plastic flow slip line failure is also related to maximum shear stress. Therefore, the maximum shear stress at different positions of the bottom plate is analyzed. Subsequently, this determines the disturbance range of the strip coal pillar to the floor stress.

The maximum and minimum principal stresses of rock mass at any point on the floor are given by

$$
\left.\begin{array}{c}
\sigma_{1} \\
\sigma_{3}
\end{array}\right\}=\frac{\sigma_{x}+\sigma_{y}}{2} \pm \sqrt{\left(\frac{\sigma_{x}+\sigma_{y}}{2}\right)^{2}+\tau_{x y}^{2}} .
$$

After the simplification to a plane problem and without considering the effect of intermediate stress $\sigma_{2}$, the maximum shear stress is equal to

$$
\tau_{\max }=\frac{\sigma_{1}-\sigma_{3}}{2}=\frac{1}{2} \sqrt{\left(\sigma_{x}-\sigma_{y}\right)^{2}+4 \tau_{x y}^{2}} .
$$

Through combining equations (4)-(6), the formula for calculating the maximum shear stress is

$$
\tau_{\max }=\sum_{i=0}^{n} \frac{q x}{\pi} \sqrt{\left(\frac{\left(a_{i}-b_{i}\right)+4 x^{2}}{\left[\left(a_{i}-y\right)^{2}+x^{2}\right]\left[\left(b_{i}-y\right)^{2}+x^{2}\right]}\right)} .
$$

3.4. Floor Yield Stress. Under the effect of the overburden load, in which the floor rock mass stress reaches the limit, the rock mass enters the plastic state. For rock materials, this means that cracks are generated inside. As the plastic failure continues to develop, the crack penetrates and eventually produces a slip failure surface.

According to plastic mechanics, an indication of plastic failure is the fact that the material enters the yield state. For the destruction of rock materials, the von Mises yield criterion is typically used to determine the state of the floor rock mass. Under certain deformation conditions, when the equivalent von Mises stress of a point in the loaded body reaches the yield stress, it is considered that the point has 
plastic failure. The calculation formula for the equivalent von Mises stress is described using

$$
\left(\sigma_{1}-\sigma_{2}\right)^{2}+\left(\sigma_{2}-\sigma_{3}\right)^{2}+\left(\sigma_{3}-\sigma_{1}\right)^{2}=2 \sigma_{s}^{2}
$$

The model was considered as a two-dimensional plane, and equation (9) was converted for the calculation of a twodimensional problem, without considering the effect of intermediate stress $\sigma_{2}$. The von Mises stresses were calculated using the following equation:

$$
\sigma_{1}^{2}+\sigma_{3}^{2}-\sigma_{1} \sigma_{3}=\sigma_{s}^{2}
$$

TABLE 1: Parameters of each scheme.

\begin{tabular}{lcc}
\hline Plan number & $\begin{array}{c}\text { Width of excavated } \\
\text { coal pillar }(\mathrm{m})\end{array}$ & $\begin{array}{c}\text { Width of retained } \\
\text { coal pillar }(\mathrm{m})\end{array}$ \\
\hline 1 & 10 & 10 \\
2 & 20 & 20 \\
3 & 30 & 30 \\
4 & 40 & 40 \\
\hline
\end{tabular}

With the combination of equations (4), (5), and (10), the von Mises stresses can be calculated as follows:

$$
\sigma_{s}=\sum_{i=0}^{n} \frac{q}{\pi} \sqrt{\frac{3 x^{2}\left[\left(a_{i}-b_{i}\right)+4 x^{2}\right]}{\left[\left(a_{i}-y\right)^{2}+x^{2}\right]\left[\left(b_{i}-y\right)^{2}+x^{2}\right]}+\left[\arctan \left(\frac{a_{i}-y}{x}\right)-\arctan \left(\frac{b_{i}-y}{x}\right)\right]^{2}} .
$$

3.5. Calculation Schemes. Under different widths of excavated and retained coal pillars, the floor is disturbed to different degrees. To determine the optimal mining plan based on the various widths of excavated and retained coal pillars, four schemes were designed for this study. By comparing and analyzing the stress and failure characteristics of the floor under different conditions, the optimal mining plan is determined. The parameters of each scheme are listed in Table 1.

According to the geological data of the Bucun coal mine [30], most parts of the floor are composed of sandstone and sandpaper shale. The physical properties of rocks are similar, and therefore, the floor rock is simplified to the same type of rock.

\section{The Effect of Strip Mining}

4.1. Shear Stress Effect. Figure 7 shows the contour of shear stress of floor rock mass under different schemes.

Figure 7 shows the shear stress contours of the floor under different mining schemes. As seen in the figure, the contours of the maximum shear stress regions appear in the shallow area of the floor in the shape of a bubble, which gradually transforms into a wave as the depth increases. When the shear stress is greater than $3.6 \mathrm{MPa}$, the shear stress isoline forms a more obvious bubble shape; when the shear stress is less than $3.6 \mathrm{MPa}$, the shear stress isoline forms a wave shape.

As the shear stress decreases, the disturbance to the bottom plate gradually decreases. By comparing the contour shapes under different conditions, the following can be concluded. When scheme 1 is adopted, the floor suffers the least disturbance, i.e., the disturbance range is mainly within the depth of 0 to $10 \mathrm{~m}$; the area with a depth of more than $10 \mathrm{~m}$ is less affected by mining. In scheme 2 , the disturbance range of the floor is further expanded, and the maximum shear stress is in the range $0-30 \mathrm{~m}$ while the maximum shear stress is less affected in the range $30-50 \mathrm{~m}$. For schemes 3 and
4, the maximum shear stress changes significantly within the range $0-50 \mathrm{~m}$.

Additionally, it can be found that the central axis of the bubble is located below the edge of each coal pillar in the shallow area; the maximum likewise appears in this area. The bubble contour is pointed upward in the direction of the coal pillar, and this characteristic becomes more obvious as the mining width increases. Below the central area of the retained coal pillar and the middle of the goaf, the maximum shear stress of the floor rock mass is small.

4.2. Influence Range of Shear Stress. To obtain the variation law of shear stress at different depths, the shear stresses were calculated at depths of 10,20,30,40, and $50 \mathrm{~m}$. The distribution curves of shear stress are presented in Figure 8.

As the depth increases, the maximum shear stress of floor rock mass decreases until it stabilizes at approximately $0.5 \mathrm{MPa}$. Therefore, the average value of $0.5 \mathrm{MPa}$ is considered as the boundary of mining influence. The influence depths of the shear stress in scheme 1 and scheme 2 are $20 \mathrm{~m}$ and $30 \mathrm{~m}$, respectively. In scheme 1 , the shear stress at $20 \mathrm{~m}$ is $0.253 \mathrm{MPa}$, which is less than $0.5 \mathrm{MPa}$. For scheme 2 , the shear stress at $30 \mathrm{~m}$ is less than $0.5 \mathrm{MPa}$. When schemes 3 and 5 are adopted, the average shear stress values at $50 \mathrm{~m}$ are $0.634 \mathrm{MPa}$ and $0.787 \mathrm{MPa}$, respectively, and the influence range of shear stress is more than $50 \mathrm{~m}$.

Furthermore, the excavation and retention widths of a strip coal pillar are the main factors affecting the shear stress of floor rock mass. As they increase, the shear stress increases as well. Taking the shear stress at a depth of $20 \mathrm{~m}$ as an example, the average value in scheme 1 is $0.253 \mathrm{MPa}$, and the maximum values in schemes 2,3 , and 4 are $1.250 \mathrm{MPa}$, 2.418 $\mathrm{MPa}$, and 3.014 $\mathrm{MPa}$, respectively.

4.3. Von Mises Stress Distribution Law. Under the impact of coal pillars, the floor rock mass will gradually enter the yield state. The von Mises yield criterion is used to assess whether 


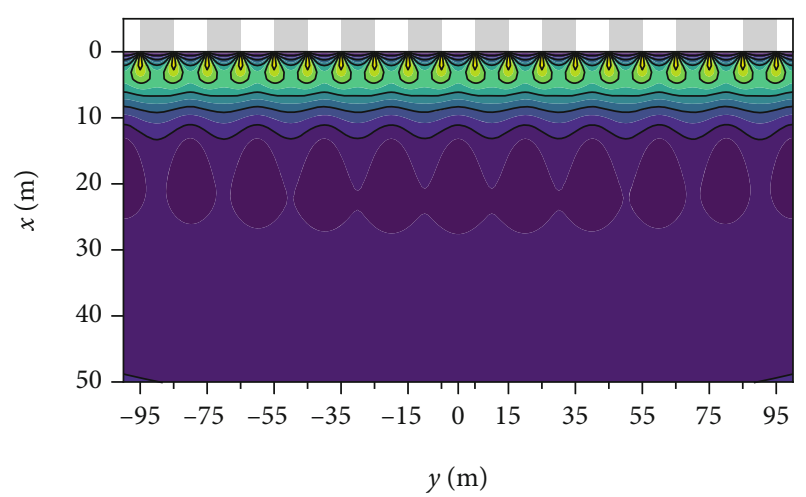

(a)

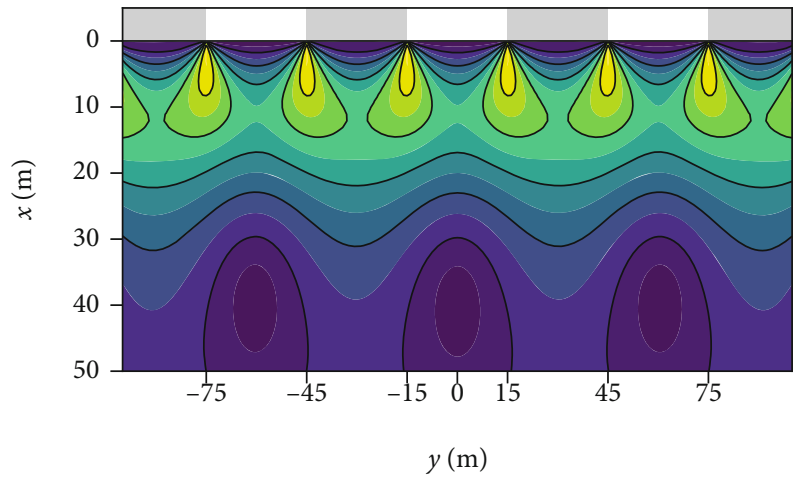

(c)

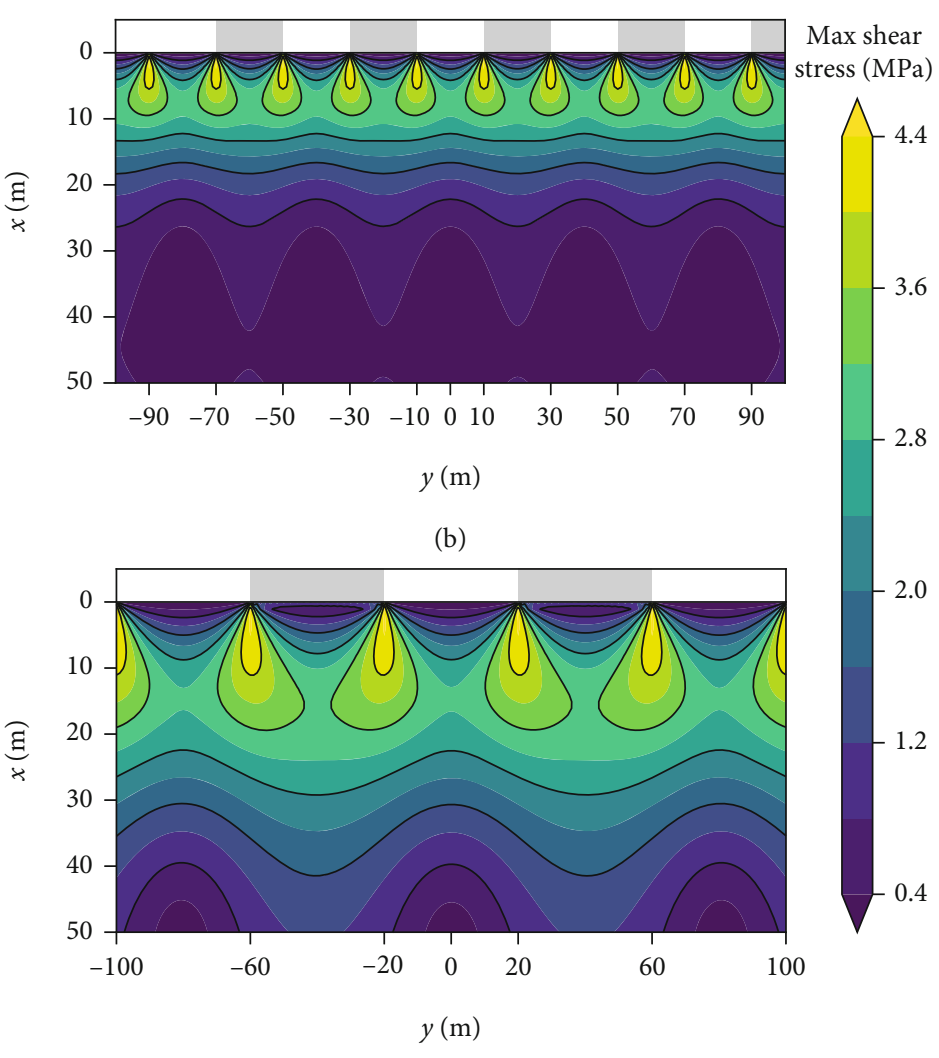

(d)

Figure 7: Cloud maps of maximum shear stress distributions when the width of the excavated coal pillar is (a) $10 \mathrm{~m}$, (b) $20 \mathrm{~m}$, (c) $30 \mathrm{~m}$, and (d) $40 \mathrm{~m}$.

the floor rock mass has entered the plastic state, and the equivalent stress value can be calculated using equation (6). Figure 9 is a contour of the von Mises equivalent stress distributions of the floor rock mass.

As shown in Figure 9, the von Mises stress at the lower part of the pillar is significantly higher than that at the lower part of the goaf. When $x$ equals 0 , the stress value at the lower part of the coal pillar is the highest, i.e., $15 \mathrm{MPa}$, while at the lower part of the goaf, it is the lowest, i.e., $0 \mathrm{MPa}$. As the depth increases, the von Mises stress in the pillar and the lower part of the goaf gradually decreases or increases and finally approaches the value of $6 \mathrm{MPa}$.

Below the coal pillar, the isoline of von Mises stress is uniformly distributed in the shape of a spindle. With the increase of the width of the coal pillar and goaf, the spindle-like area gradually increases. For scheme 1, the maximum depth of the spindle region is $10.8 \mathrm{~m}$, while for schemes 2 and 3 they are $20.95 \mathrm{~m}$ and $31.4 \mathrm{~m}$, respectively. When scheme 4 is adopted, the maximum depth is $41.8 \mathrm{~m}$.

4.4. Depth of Floor Failure. To ensure that there is no water inrush in the mining process of the working face, it is necessary to ensure that the floor has a certain thickness of waterproof layer. If the average yield stress of the floor rock mass is $\sigma_{\mathrm{s}}=9.5 \mathrm{MPa}$, the shape and depth of the floor failure area are shown in Figure 10.
As seen in Figure 10, the maximum failure depths of schemes $1,2,3$, and 4 are $6.88 \mathrm{~m}, 13.72 \mathrm{~m}, 20.58 \mathrm{~m}$, and $27.44 \mathrm{~m}$, respectively.

According to the original data of Bucun coal mine, the height of the permeable passage is $10 \mathrm{~m}$, and the minimum depth of the confined aquifer on the floor of the 911 working face is $42.5 \mathrm{~m}$. The thickness of the isolation rock strata of schemes $1,2,3$, and 4 is $25.62 \mathrm{~m}, 18.78 \mathrm{~m}, 11.92 \mathrm{~m}$, and $5.06 \mathrm{~m}$, respectively.

In scheme 4, the failure depth of the floor is large and the thickness of the isolated rock layer is small; therefore, it is difficult to meet the safety requirements. Although the failure depth of scheme 3 is relatively smaller, it is still significantly affected by shear stress at a depth of $20 \mathrm{~m}$. To ensure mining safety, scheme 1 and scheme 2 should be selected.

After mining a face, it is necessary to move the mining equipment to the next face. When scheme 1 is adopted, the working face width is $10 \mathrm{~m}$, and when scheme 2 is adopted, the working face width is $20 \mathrm{~m}$. Scheme 2 has fewer working surfaces than scheme 1 , which can effectively reduce the number of equipment moves. Therefore, from a financial point of view, it is more efficient to mine with scheme 2 . In combination with the west wing of the 911 mining area, there are four tendencies in the lower working face of 9115 and the upper working face of 9115 . When the width of the mining strip reaches 20 to $23 \mathrm{~m}$, there is no water inrush. Thus, the recommended mining plan is scheme 2 . 


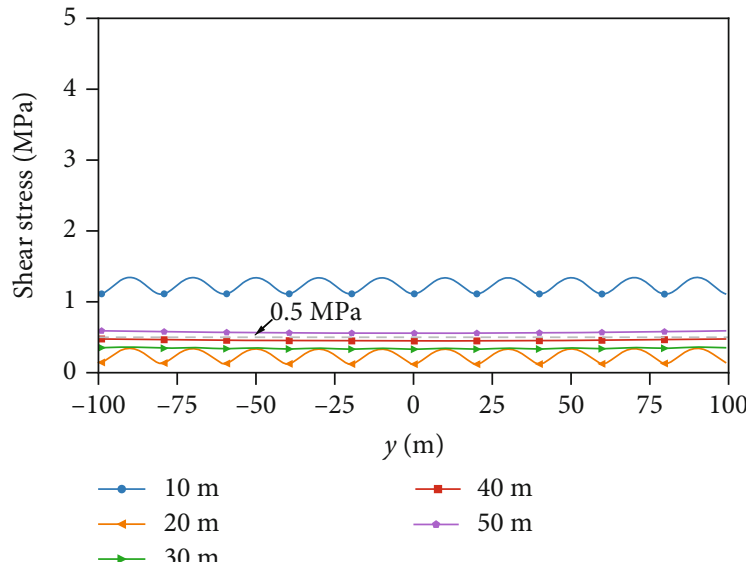

(a)

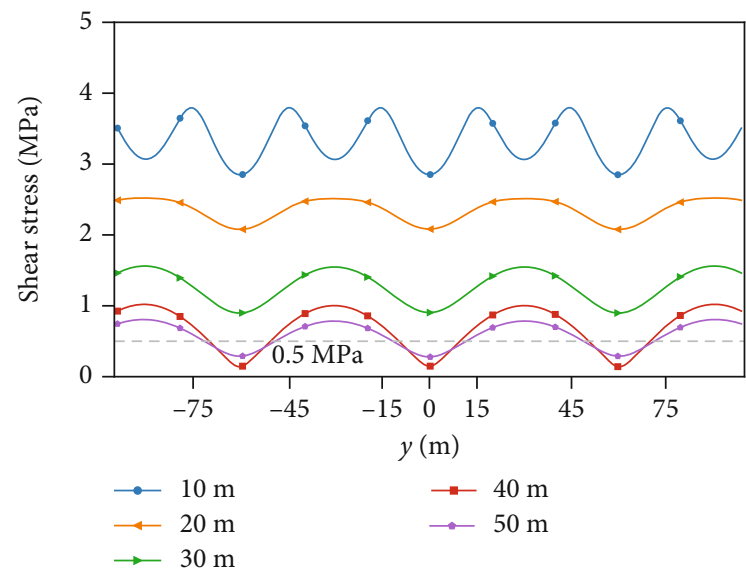

(c)

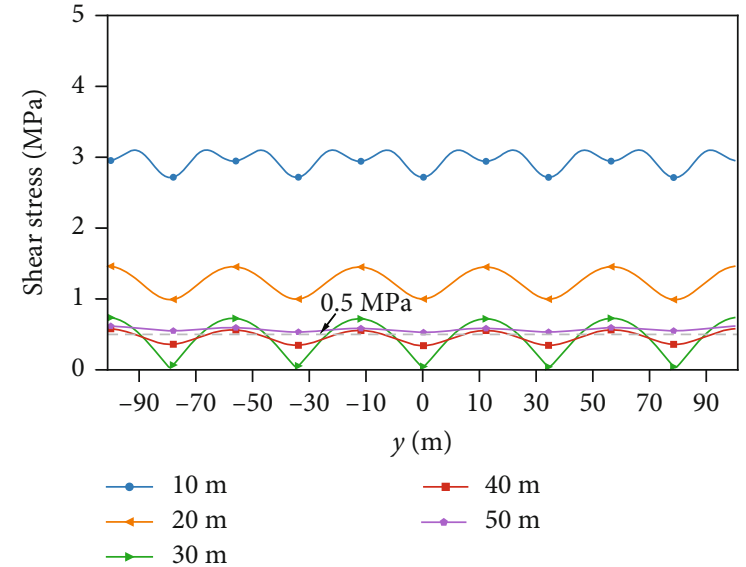

(b)

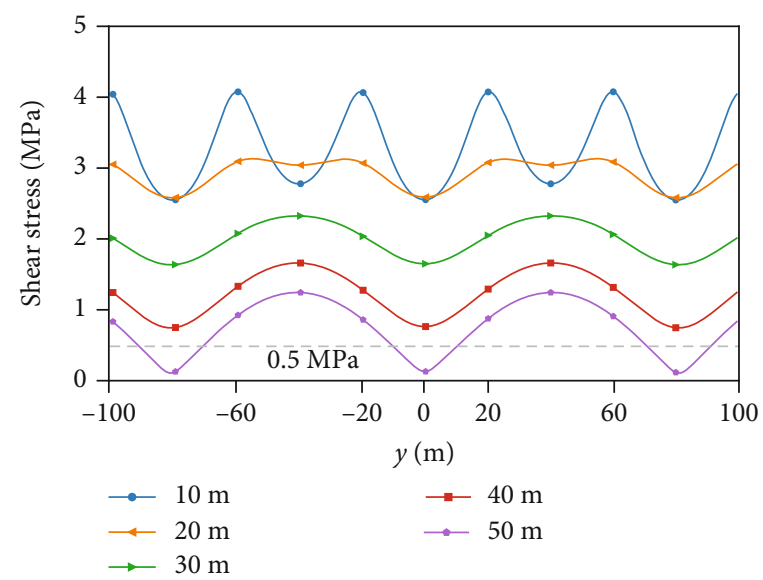

(d)

FIGURE 8: Shear stress distributions at various depths: (a) width of excavated coal pillar is $10 \mathrm{~m}$, (b) width of excavated coal pillar is $20 \mathrm{~m}$, (c) width of excavated coal pillar is $30 \mathrm{~m}$, and (d) width of excavated coal pillar is $40 \mathrm{~m}$.

\section{Influence of Backfill Replacement Mining}

First, the scheme of excavating $20 \mathrm{~m}$ and reserving $20 \mathrm{~m}$ was adopted in Bucun coal mine, and there was no water inrush in the process of mining. After strip mining, high water content material was backfilled to replace the coal pillar in this area. To avoid water inrush from the floor in the process of replacement mining, the failure depth of the floor, after replacement mining, must be studied.

As shown in Figures 3(c) and 3(d), the roof is supported by coal pillars and filling body together, and the load of coal pillar changes after backfill replacement mining. Therefore, goaf backfill and coal pillar mining are simulated through changing the range of load. Moreover, the load on the boundary is changed according to the width of the supporting material.

5.1. Influence of Multiple Mining on Shear Stress. Due to multiple mining, the maximum shear stress of the floor rock mass changed. Additionally, the maximum shear stresses of the floor during strip mining, first backfill replacement mining, and second backfill replacement mining were compared.
Figure 11 shows the distribution curves of shear stress at different depths.

The effect of the two backfill replacement mining processes on floor stress is the same. The maximum shear stress distribution curve is the same, but the position of the peak and valley changes. When the depth is $10 \mathrm{~m}, 20 \mathrm{~m}, 30 \mathrm{~m}$, and $40 \mathrm{~m}$, the average maximum shear stress is $1.173 \mathrm{MPa}$, $1.186 \mathrm{MPa}, 0.911 \mathrm{MPa}$, and $0.858 \mathrm{MPa}$, respectively.

Moreover, the comparison with the shear stress of the floor after strip mining shows that the maximum shear stress in the shallow part of the floor decreases after backfill replacement mining and gradually approaches to the maximum shear stress in the deep part. When the depth is $10 \mathrm{~m}$, the average maximum shear stress decreases by $1.902 \mathrm{MPa}$ after backfill replacement mining, and when the depth is $20 \mathrm{~m}, 30 \mathrm{~m}$, and $40 \mathrm{~m}$, the von Mises stress values decrease to $0.194 \mathrm{MPa}, 0.061 \mathrm{MPa}$, and $0.185 \mathrm{MPa}$, respectively. These results suggest that the degree of disturbance in the deep part does not obviously change after backfill replacement mining.

5.2. Effect of Replacement Mining on Floor Fracture. According to the previous analysis, the yield stress $\sigma_{\mathrm{s}}$ of the floor 


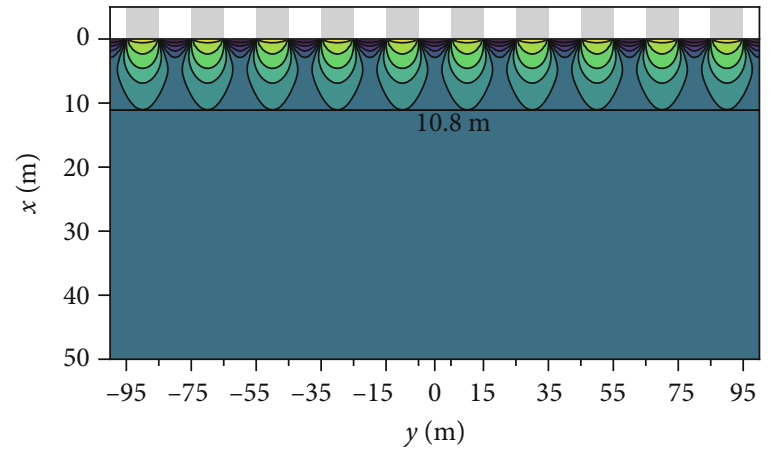

(a)

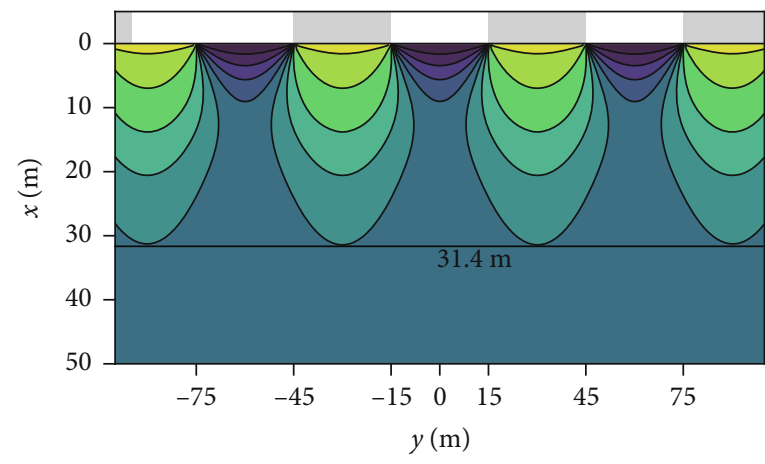

(c)

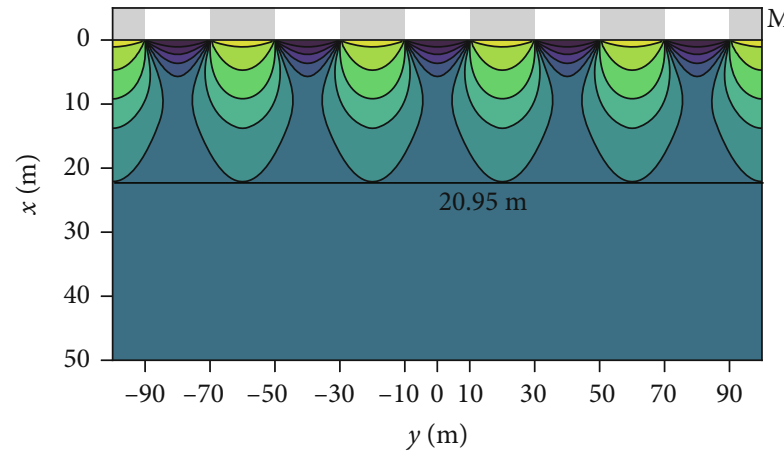

(b)



(d)

FIGURE 9: Cloud maps of von Mises stress distributions when the width of the excavated coal pillar is (a) $10 \mathrm{~m}$, (b) $20 \mathrm{~m}$, (c) $30 \mathrm{~m}$, and (d) $40 \mathrm{~m}$.

rock mass is $9.5 \mathrm{MPa}$, and the plastic zone formed is shown in Figures 12(a) and 12(b).

Figure 12(a) shows the shape of the plastic zone of the floor rock mass after the first replacement mining. After that, a new plastic zone is formed on the basis of the original plastic zone. The new zone appears in the lower part of the original goaf, but the maximum failure depth of the newly formed zone is $4.41 \mathrm{~m}$, which does not exceed the depth of the original one.

Additionally, Figure 12(b) shows the plastic zone of the floor formed after the second backfill replacement mining, which is similar to the plastic zone formed in the first one, while a new plastic zone is formed in the lower part of the replacement material. Under the influence of multiple mining, the rock mass is destroyed in the range of $4.41 \mathrm{~m}$ floor depth.

\section{Field Measurements}

6.1. Monitoring Program. To further study the mechanical behavior of floor rock mass under the influence of mining, measuring stations were set up in the 9113 and 9111 working faces. The layout of the measuring station and working face is shown in Figure 13.

The measuring station 1\# was set up at the 9113 working face, which mainly monitored the deformation and failure of the floor in the process of strip mining. The 9113 working face was in the west wing of the 911 district, and the measuring station was located at the upper exit of the working face. Five angle transducers were arranged to monitor the inclination of the borehole to the 9113 working face, and they were installed at depths of $5 \mathrm{~m}, 12 \mathrm{~m}, 19 \mathrm{~m}, 25 \mathrm{~m}$, and $30 \mathrm{~m}$.

Furthermore, the measuring station arranged in the 9111 working face mainly monitored the floor deformation and failure before and after the replacement mining of coal pillar. This measuring station was located at the exit of the 9111 working face, and the strain sensor was embedded before the high water content material filled the original strip falling area. Five measuring points were arranged, and the vertical depths (vertical floor depths) were $7 \mathrm{~m}, 9 \mathrm{~m}, 11 \mathrm{~m}, 13 \mathrm{~m}$, and $15 \mathrm{~m}$, respectively.

6.2. Prediction of Rock Mass Mechanical Behavior. According to the previous analysis, the stress values of different positions of floor rock mass are calculated. When these are combined with the physical equation, the strain of rock mass can be calculated at any point and its mechanical behavior can be predicted. According to the rock mechanics parameter of the floor, the elastic modulus is $2.5 \mathrm{GPa}$, and Poisson's ratio is $\mu=0.15$.

In addition, measuring station $1 \#$ used angle transducers for monitoring, which could monitor the shear strain of rock floor mass. Equation (8) gives the calculation method of the maximum shear stress at any point on the floor. The shear 


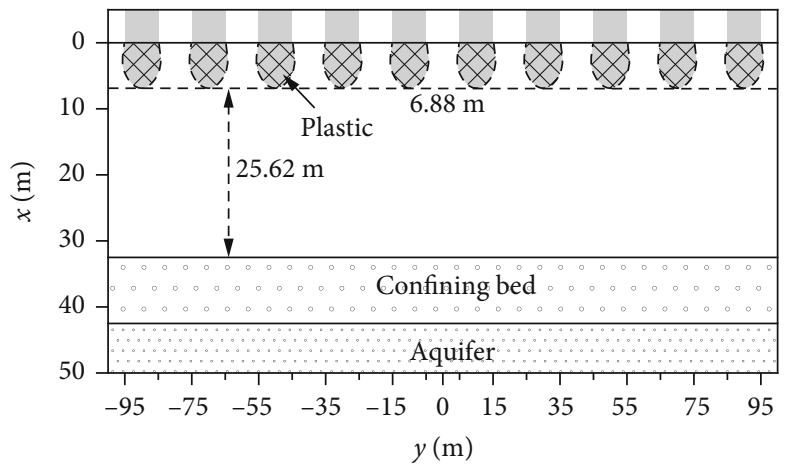

(a)

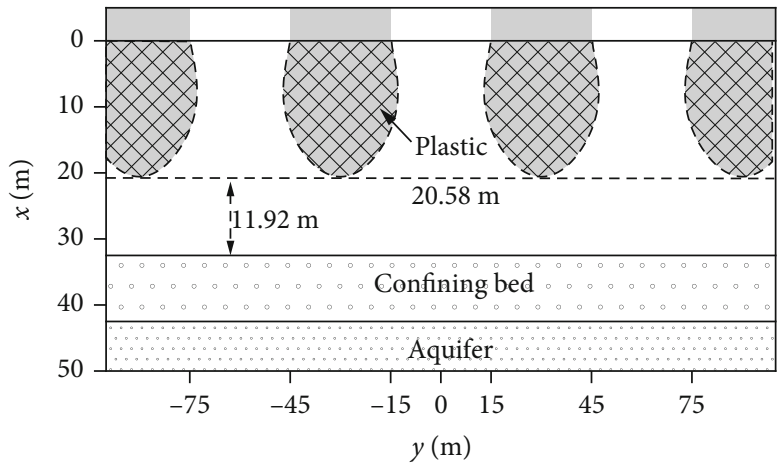

(c)

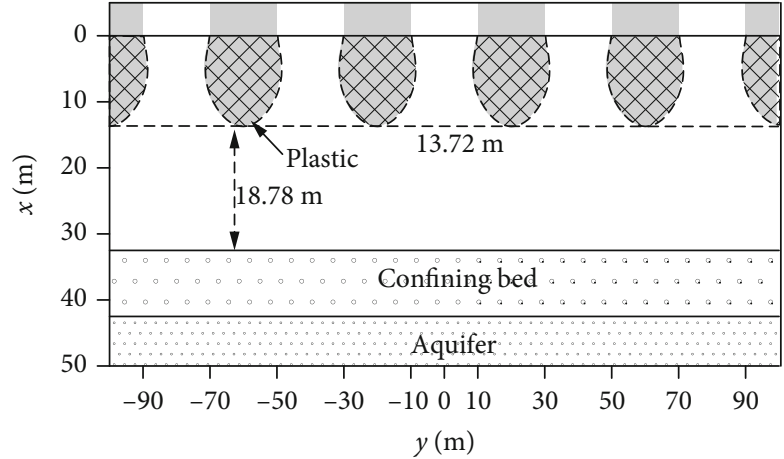

(b)

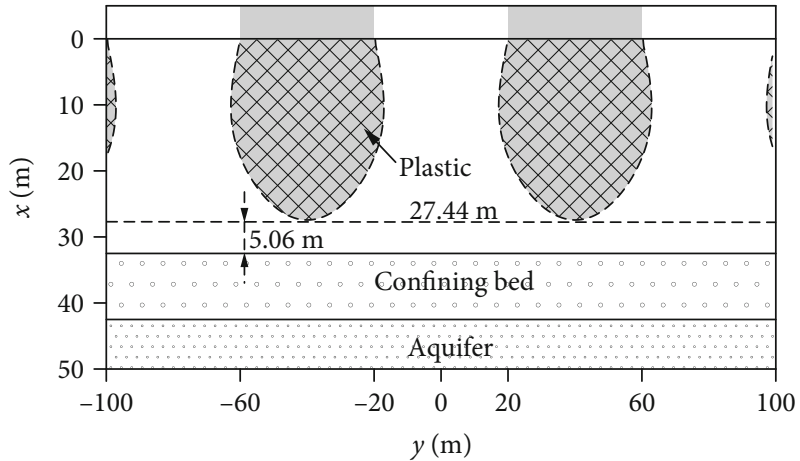

(d)

FIgURE 10: Floor failure area distribution patterns: (a) width of excavated coal pillar is $10 \mathrm{~m}$, (b) width of excavated coal pillar is $20 \mathrm{~m}$, (c) width of excavated coal pillar is $30 \mathrm{~m}$, and (d) width of excavated coal pillar is $40 \mathrm{~m}$.

strain of floor rock mass is calculated according to the physical equation of the plane strain problem given in

$$
\begin{aligned}
\gamma_{\max } & =\frac{2(1+\mu)}{E} \tau_{\max } \\
& =\sum_{i=0}^{n} \frac{2(1+\mu) q x}{E \pi} \sqrt{\frac{\left(a_{i}-b_{i}\right)^{2}+4 x^{2}}{\left[\left(a_{i}-y\right)^{2}+x^{2}\right]\left[\left(b_{i}-y\right)^{2}+x^{2}\right]}} .
\end{aligned}
$$

The strain value at any point on the floor can be calculated using equation (12). The angular displacement of the point can be obtained by transforming the angle from radians to degrees.

Moreover, measuring station 2\# used strain transducers for monitoring, which could monitor the strain of the floor rock mass. Equation (4) gives the calculation method of vertical stress at any point at the bottom of the station. As previously, the shear strain of floor rock mass is calculated according to the physical equation of the plane strain problem as follows:

$$
\begin{aligned}
\varepsilon_{x}= & \sum_{i=0}^{n} \frac{q(1+\mu)}{E \pi}\left((1+2 \mu)\left[\arctan \left(\frac{a_{i}-y}{x}\right)-\arctan \left(\frac{b_{i}-y}{x}\right)\right]\right. \\
& \left.+x \frac{a_{i}^{2}\left(y-b_{i}\right)+b_{i}^{2}\left(a_{i}-y\right)+\left(a_{i}-b_{i}\right)\left(x^{2}-y^{2}\right)}{\left[\left(a_{i}-y\right)^{2}+x^{2}\right]\left[\left(b_{i}-y\right)^{2} x^{2}\right]}\right) .
\end{aligned}
$$

6.3. Observation Results. To prevent the deformation law of the floor being affected by mining, the research data after the mining in the area around each station were collected. The monitoring results and theoretical settlement results of floor deformation after mining are shown in Figure 14. Here, Figure 14(a) shows the theoretical calculation results and monitoring angle of the angle transducers. Figure 14(b) shows the strain value of the rock as measured by the strain sensor.

Figure 14(a) shows the results of field observation. When the depth is $5 \mathrm{~m}$, the shear deformation of the floor rock mass reaches its maximum. The shear deformation decreases with the increase of depth and becomes stable when the depth is greater than $19 \mathrm{~m}$. This result is in good agreement with the theoretical calculation. According to that, the shear deformation of the floor rock mass also reaches its maximum value at approximately $5 \mathrm{~m}$, which will gradually decrease with the increase of the depth, while the depth of the significant influence area is $19 \mathrm{~m}$.

Based on Figure 14(b), the vertical deformation of the floor rock mass reaches its maximum at around $5 \mathrm{~m}$. The vertical strain decreases when the depth is greater than $5 \mathrm{~m}$. The general tendency is a decreasing one, and when the depth is less than $9 \mathrm{~m}$, the effect is more significant. From the theoretical calculation, the deformation of floor rock mass decreases with the increase of depth, which is consistent with the results of field monitoring.

According to the field monitoring results, the mechanical behavior of rock mass changes with the increase of depth. In 


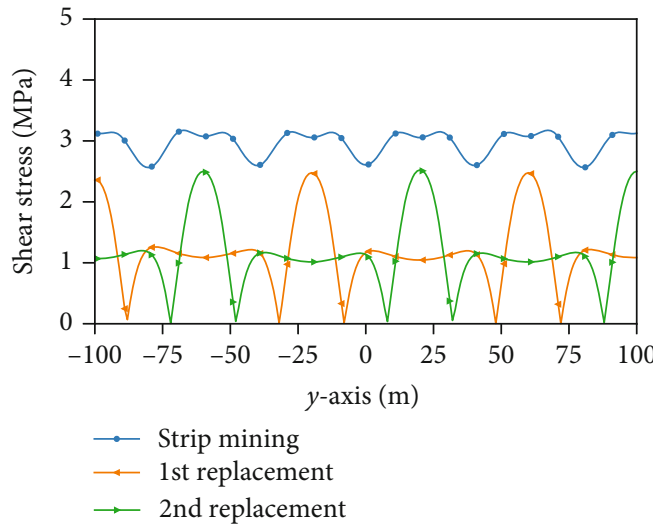

(a)

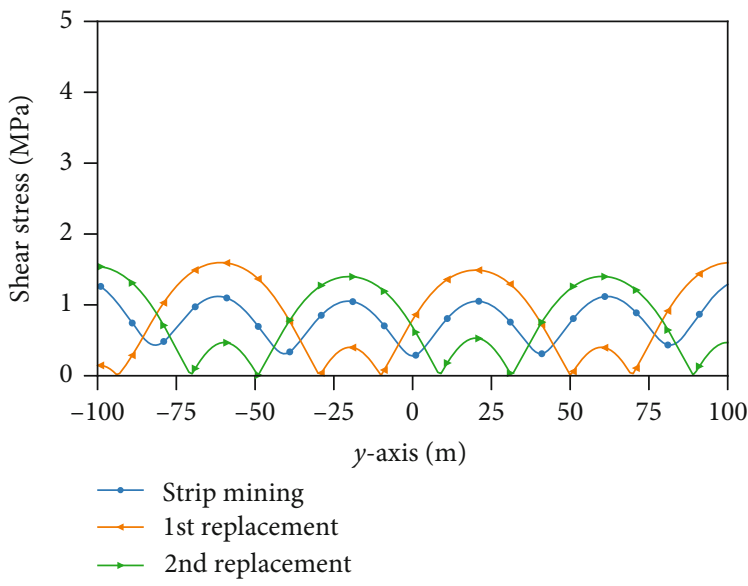

(c)

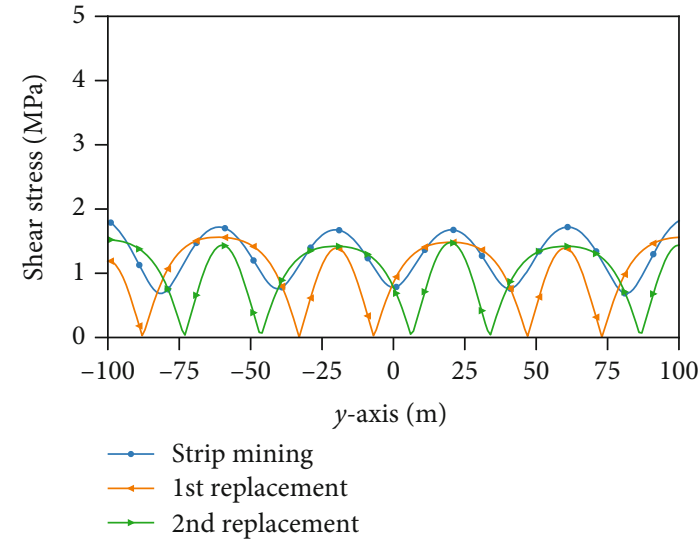

(b)

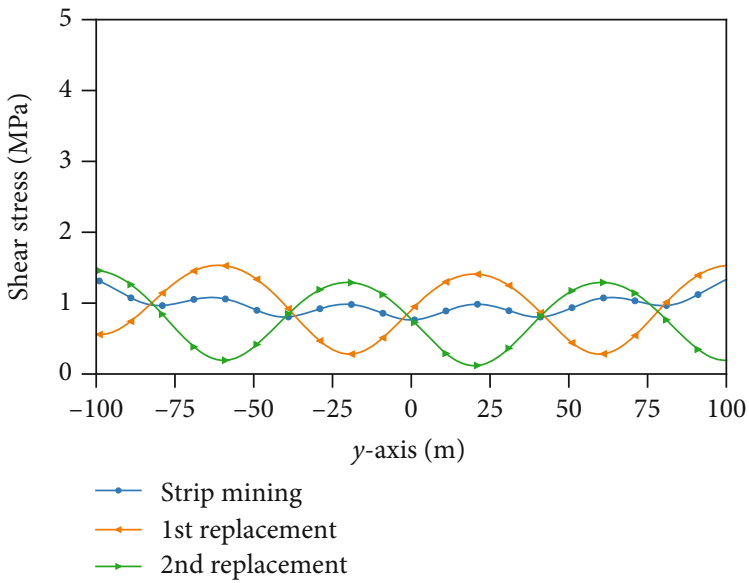

(d)

Figure 11: Characteristics of shear stress distribution at various depths: (a) depth of $10 \mathrm{~m}$, (b) depth of $20 \mathrm{~m}$, (c) depth of $30 \mathrm{~m}$, and (d) depth of $40 \mathrm{~m}$.

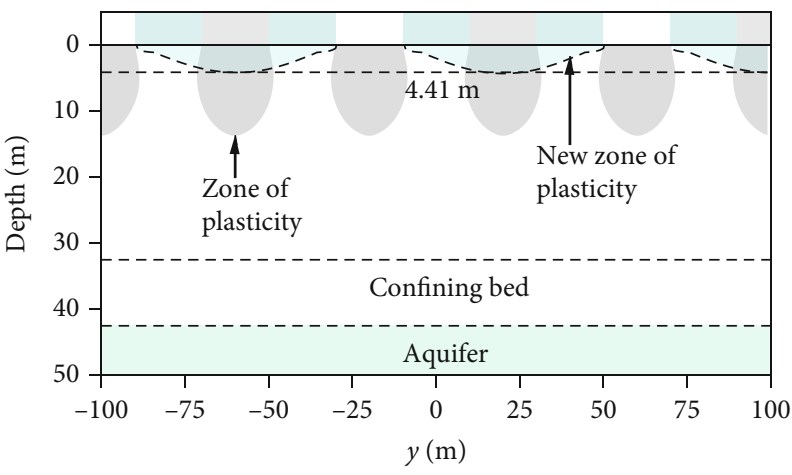

(a)

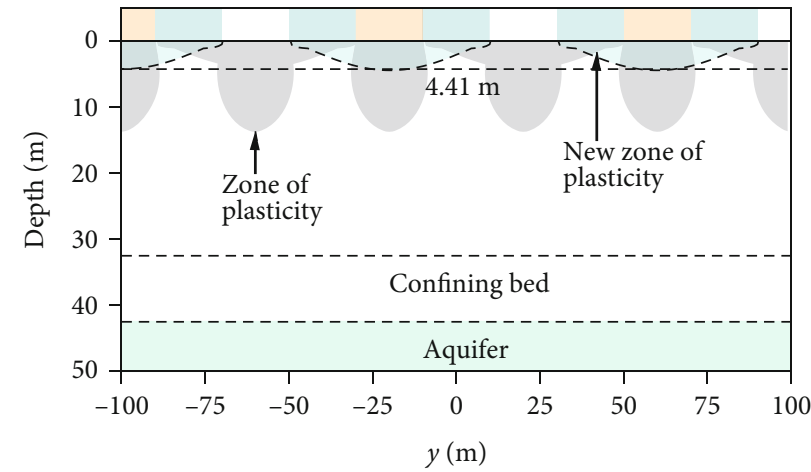

(b)

Figure 12: Plastic zone distributions of replacement mining floor: (a) first backfill replacement mining; (b) second backfill replacement mining.

Figure 14(a), it can be seen that the deformation of the floor rock mass is relatively continuous and tends to be stable when the depth is greater than $19 \mathrm{~m}$. However, in Figure 14(b), it can be seen that a deformation discontinuity occurs at a depth of $9 \mathrm{~m}$. The results show that when the depth is $9 \mathrm{~m}$, the floor rock mass enters the plastic state, the rock mass is discontinuous, and the integrity is destroyed.

\section{Discussion}

In this study, we found that the widths of excavated and retained coal pillars are the key factors affecting the development of floor fracture. By adjusting the width of retained pillar and excavation width, the failure depth and mechanical behavior of floor rocks can be changed. When the coal seam 


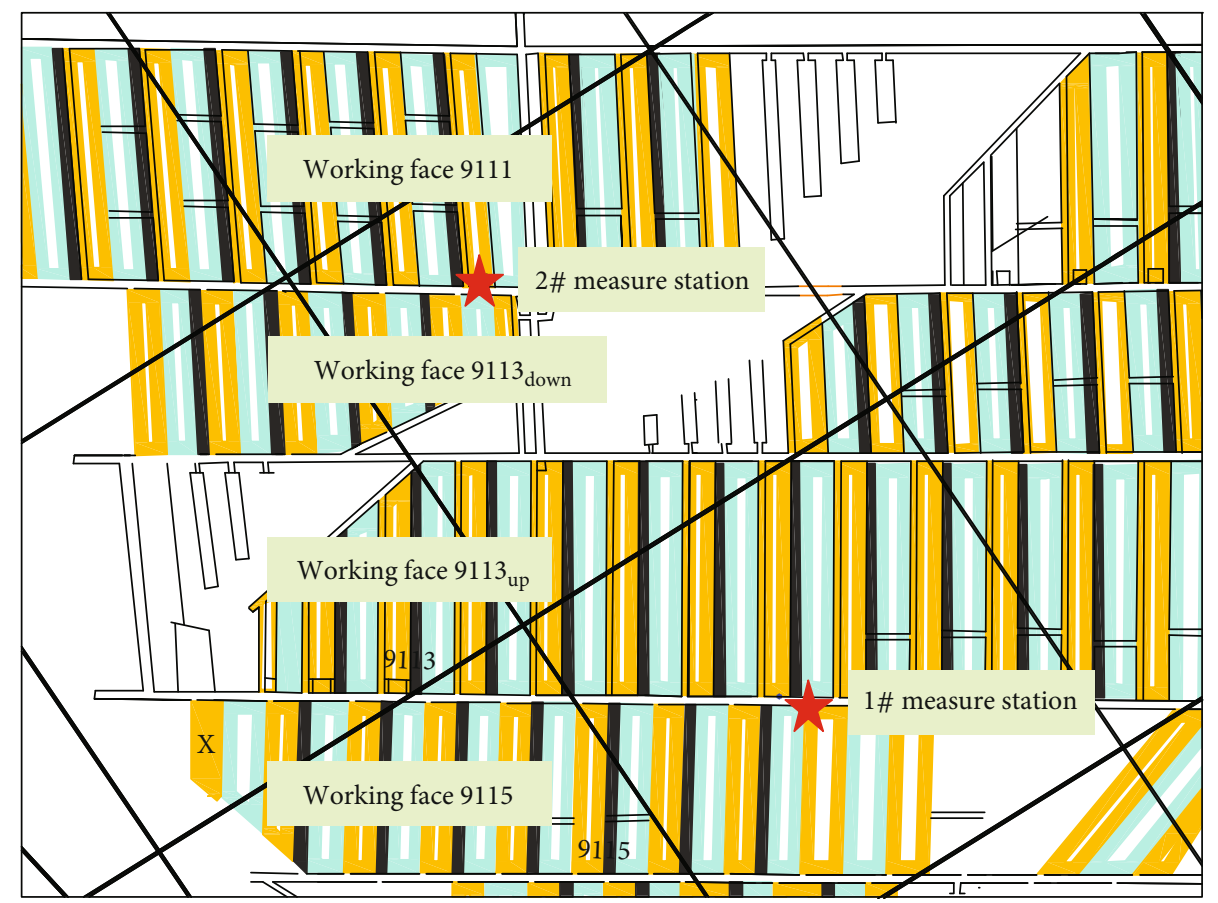

FIgURE 13: Station location.

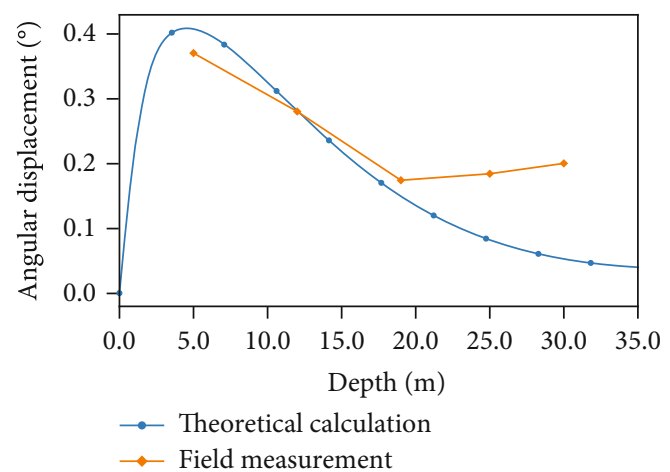

(a)

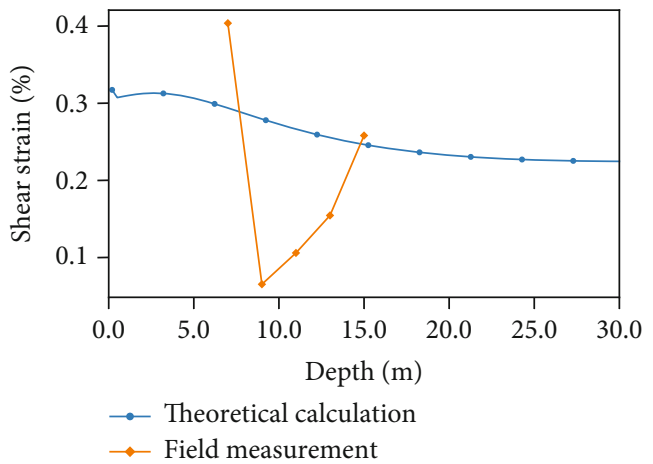

(b)

FIGURE 14: Deformation law of floor rock mass: (a) measuring station 1\#; (b) measuring station 2\#.

is not excavated, the force on the floor is uniformly distributed, and with the increase of the width of strip mining, the stress is concentrated leading to an increasing failure depth of the floor. According to the resistivity of strip coal pillar floor by $\mathrm{Yu}$ et al. [30], the failure depth is $50.7 \mathrm{~m}$ when the width of the strip coal pillar is $15 \mathrm{~m}$, and the failure depth increases gradually with the increase of mining width. According to previous research by Zha et al. [33], when the longwall face is used for normal mining, the maximum floor failure depth is $76.18 \mathrm{~m}$. Therefore, the use of strip coal pillar and the reduction of the excavation width are beneficial to reduce the failure depth of floor rock mass.

Additionally, a strong relationship between cracks and yield state of rock mass has been reported in the literature. The characteristics and density of microcracks can be ana- lyzed by the yield state of the floor rock mass. The von Mises yield criterion reflects the spatial shape and the threatening degree of rock mass failure. With the increase of von Mises stress, the fracture density of rock mass increases and the failure direction is related to the specific stress state. With the depth increase of the floor rock mass, the crack density decreases gradually, and the possibility of forming a permeable passage decreases as well. At the plastic state, the direction of plastic flow is related to the maximum shear stress. In this study, we found that shear stress is concentrated at the lower part of the boundary on both sides of the coal pillar while it is small in the middle area of the bottom of the coal pillar. Based on these data, we can infer that there is a rock mass failure surface below the edge of the coal pillar. As a result, these findings can help us predict the location of water inrush. 
In order to prevent the accident of water inrush in confined water and improve the safety of coal mining on it, attention should be paid into the following aspects: (a) an exhaustive exploration should be carried out for the floor aquifer to determine the distribution of confined water and the value of water pressure; (b) strip mining can effectively reduce the floor failure depth, and in combination with high water content material backfilling replacement, it does not only reduce the disturbance to the floor rock mass but also improves the coal resource recovery rate; and (c) reducing the size of strip mining can effectively reduce the degree of disturbance of the floor and reduce the failure depth of the floor by increasing the strength of the floor rock mass.

\section{Conclusions}

This study examines the safe mining of coal resources on a confined water aquifer. The influence of stress disturbance on rock mass at different depths is analyzed using a mechanical model, and the failure depth of floor before and after coal seam mining is determined.

Based on the elastic mechanics theory, a mechanical model of strip mining and filling material replacement of the remaining coal pillars is constructed, the expression of the floor stress distribution is given, and its evolution law is revealed. Results show that the mining and coal pillar widths are the main influencing factors of floor stress distribution. With an increase of their values (the widths of working faces and coal pillars), the floor stress influence area gradually increases as well.

Then, according to the von Mises yield criterion, the failure depth of the floor rock mass is studied, and the equivalent expressions of the stress at different depths are given. Under the influence of coal seam mining, the rock mass of the floor has a certain depth of damage, and its range gradually decreases as the depth increases. From the calculation results, the maximum depth of floor rock failure before and after replacement is $13.72 \mathrm{~m}$, which can meet the requirements for water isolation.

Finally, the field measurement results indicate that as the depth increases, the deformation of the floor rock mass gradually decreases, and its mechanical behavior is consistent with the theoretical calculation results. The use of strip mining significantly affects the depth of the area to $19 \mathrm{~m}$, and the use of filling materials to replace the coal pillars had a significant influence depth of $9 \mathrm{~m}$.

\section{Data Availability}

In our manuscript, the experiment and test data used to support the findings of this study are available from the corresponding author upon request.

\section{Conflicts of Interest}

The authors declare that they have no conflicts of interest.

\section{Acknowledgments}

The research was supported by the independent research project of State Key Laboratory of Coal Resources and Safe Mining, CUMT (SKLCRSM19X008), and National Natural Science Foundation of China (Grant no. 52074265).

\section{References}

[1] Z. Meng, G. Li, and X. Xie, "A geological assessment method of floor water inrush risk and its application," Engineering Geology, vol. 143-144, pp. 51-60, 2012.

[2] L. Meng, Q. Y. Feng, and Q. Li, "Coupled simulation-optimization model for draining confined aquifer via underground boreholes to prevent water inrush of coal mines," Environmental Earth Sciences, vol. 77, no. 17, pp. 1-20, 2018.

[3] D. Donglin, S. Wenjie, and X. Sha, "Water-inrush assessment using a gis-based Bayesian network for the 12-2 coal seam of Kailuan Donghuantuo Coal Mine coal mine in China," Mine Water and the Environment, vol. 31, no. 2, pp. 138-146, 2012.

[4] Y. L. Jiang, D. F. Zhang, K. Wang, and X. Q. Zhang, "Mininginduced damage characteristics of floors during fully mechanized caving mining: a case study," Advances in Materials Science and Engineering, vol. 2018, 11 pages, 2018.

[5] J. A. Wang and H. D. Park, "Coal mining above a confined aquifer," International Journal Of Rock Mechanics And Mining Sciences, vol. 40, no. 4, pp. 537-551, 2003.

[6] W. B. Zhu, S. C. Yu, D. Y. Xuan, Z. J. Shan, and J. L. Xu, "Experimental study on excavating strip coal pillars using caving zone backfill technology," Arabian Journal of Geosciences, vol. 11, no. 18, p. 554, 2018.

[7] Y. Zhao, H. Zhou, J. Zhong, and D. Liu, "Study on the relation between damage and permeability of sandstone at depth under cyclic loading," International Journal of Coal Science \& Technology, vol. 6, no. 4, pp. 479-492, 2019.

[8] B. Guo, T. Cheng, L. Wang, T. Luo, and X. Yang, "Physical simulation of water inrush through the mine floor from a confined aquifer," Mine Water and the Environment, vol. 37, no. 3, pp. 577-585, 2018.

[9] Z. Li, S. Yu, W. Zhu et al., "Dynamic loading induced by the instability of voussoir beam structure during mining below the slope," International Journal of Rock Mechanics and Mining Sciences, vol. 132, article 104343, 2020.

[10] J. Sun, L. G. Wang, and G. M. Zhao, "Failure characteristics and confined permeability of an inclined coal seam floor in fluid-solid coupling," Advances in Civil Engineering, vol. 2018, 12 pages, 2018.

[11] J. Sun, Y. Hu, and G. Zhao, "Relationship between water inrush from coal seam floors and main roof weighting," International Journal of Mining Science and Technology, vol. 27, no. 5, pp. 873-881, 2017.

[12] A. Li, Y. Liu, L. Mou, and K. Li, "Numerical analysis and case study on the mitigation of mining damage to the floor of no. 5 coal seam of Taiyuan group by grouting," Journal of the Southern African Institute of Mining and Metallurgy, vol. 118, no. 5, pp. 461-470, 2018.

[13] S. C. Zhang, W. J. Guo, and Y. Y. Li, "Experimental simulation of water-inrush disaster from the floor of mine and its mechanism investigation," Arabian Journal of Geosciences, vol. 10, no. 22 , p. $503,2017$. 
[14] A. Li, Q. Ma, Y. Lian, L. Ma, Q. Mu, and J. Chen, "Numerical simulation and experimental study on floor failure mechanism of typical working face in thick coal seam in Chenghe mining area of Weibei, China," Environmental Earth Sciences, vol. 79, no. 5 , p. $118,2020$.

[15] D. Xu, S. Peng, S. Xiang, M. Liang, and W. Liu, "The effects of caving of a coal mine's immediate roof on floor strata failure and water inrush," Mine Water and the Environment, vol. 35, no. 3, pp. 337-349, 2016.

[16] S. Q. Liu, Y. Fei, Y. C. Xu, L. Huang, and W. Y. Guo, "Full-floor grouting reinforcement for working faces with large mining heights and high water pressure: a case study in China," Mine Water and the Environment, vol. 39, no. 2, pp. 268-279, 2020.

[17] C. H. Han, W. J. Zhang, W. W. Zhou et al., "Experimental investigation of the fracture grouting efficiency with consideration of the viscosity variation under dynamic pressure conditions," Carbonates and Evaporites, vol. 35, no. 2, p. 30, 2020.

[18] W. B. Liu, J. M. Xu, W. B. Zhu, and S. H. Wang, "A novel short-wall caving zone backfilling technique for controlling mining subsidence," Energy Science \& Engineering, vol. 7, no. 5, pp. 2124-2137, 2019.

[19] B. Wang, F. Dang, W. Chao, Y. Miao, J. Li, and F. Chen, "Surrounding rock deformation and stress evolution in pre-driven longwall recovery rooms at the end of mining stage," International Journal of Coal Science \& Technology, vol. 6, no. 4, pp. 536-546, 2019.

[20] N. Jiang, C. Wang, H. Pan, D. Yin, and J. Ma, "Modeling study on the influence of the strip filling mining sequence on mining-induced failure," Energy Science \& Engineering, vol. 8, no. 6, pp. 2239-2255, 2020.

[21] Y. Yu, K. Z. Deng, Y. Luo, S. E. Chen, and H. F. Zhuang, “An improved method for long-term stability evaluation of strip mining and pillar design," International Journal of Rock Mechanics and Mining Sciences, vol. 107, pp. 25-30, 2018.

[22] L. Li, F. Li, Y. Zhang, D. Yang, and X. Liu, "Formation mechanism and height calculation of the caved zone and waterconducting fracture zone in solid backfill mining," International Journal of Coal Science \& Technology, vol. 7, no. 1, pp. 208-215, 2020.

[23] C. X. Wang, Y. Lu, B. T. Shen, Y. Y. Li, and Y. B. Liang, "Design and monitoring of cpb replacement mining rscp: a case study in china," Energy Sources, Part A: Recovery, Utilization, and Environmental Effects, vol. 43, pp. 80-95, 2019.

[24] D. R. Tesarik, J. B. Seymour, and T. R. Yanske, "Long-term stability of a backfilled room-and-pillar test section at the buick mine, Buick Mine, Missouri, USA," International Journal of Rock Mechanics and Mining Sciences, vol. 46, no. 7, pp. 1182-1196, 2009.

[25] J. H. Zhai, D. L. Liu, G. Li, and F. T. Wang, "Floor failure evolution mechanism for a fully mechanized longwall mining face above a confined aquifer," Advances in Civil Engineering, vol. 2019, 11 pages, 2019.

[26] H. Lu, X. Liang, N. Shan, and Y. Zhang, "Study on the stability of the coal seam floor above a confined aquifer using the structural system reliability method," Geofluids, vol. 2018, 15 pages, 2018.

[27] J. Hao, Y. Shi, J. Lin, X. Wang, and H. Xia, "The effects of backfill mining on strata movement rule and water inrush: a case study," Processes, vol. 7, no. 2, p. 66, 2019.

[28] W. Cai, Z. Chang, D. Zhang, X. Wang, W. Cao, and Y. Zhou, "Roof filling control technology and application to mine road- way damage in small pit goaf," International Journal of Mining Science and Technology, vol. 29, no. 3, pp. 477-482, 2019.

[29] X. Zhu, G. Guo, H. Liu, X. Peng, and X. Yang, "Research on the stability evaluation model of composite support pillar in backfill-strip mining," Mathematical Problems in Engineering, vol. 2020, 11 pages, 2020.

[30] S. C. Yu, J. M. Xu, W. B. Zhu, S. H. Wang, and W. B. Liu, "Development of a combined mining technique to protect the underground workspace above confined aquifer from water inrush disaster," Bulletin of Engineering Geology and the Environment, vol. 79, no. 7, pp. 3649-3666, 2020.

[31] W. Zhu, J. Xu, J. Xu, D. Chen, and J. Shi, "Pier-column backfill mining technology for controlling surface subsidence," International Journal of Rock Mechanics and Mining Sciences, vol. 96, pp. 58-65, 2017.

[32] X. Y. Hu, H. L. Zhang, and L. G. Wang, "Analysis on stress concentration factors of roadway surrounding rock affected by cross mining," Chinese Journal of Underground Space and Engineering, vol. 11, no. 3, pp. 658-664, 2015.

[33] H. Zha, W. Liu, and Q. Liu, "Physical simulation of the waterconducting fracture zone of weak roofs in shallow seam mining based on a self-designed hydromechanical coupling experiment system," Geofluids, vol. 2020, 14 pages, 2020. 